This item was submitted to Loughborough's Research Repository by the author.

Items in Figshare are protected by copyright, with all rights reserved, unless otherwise indicated.

\title{
Self-determination in recreational exercise: Associations with lapse and post- lapse emotions
}

PLEASE CITE THE PUBLISHED VERSION

https://doi.org/10.1016/j.psychsport.2019.101548

PUBLISHER

(C) Elsevier

VERSION

AM (Accepted Manuscript)

\section{PUBLISHER STATEMENT}

This paper was accepted for publication in the journal Psychology of Sport and Exercise and the definitive published version is available at https://doi.org/10.1016/j.psychsport.2019.101548

LICENCE

CC BY-NC-ND 4.0

\section{REPOSITORY RECORD}

Murphy, Stephen, and lan Taylor. 2019. "Self-determination in Recreational Exercise: Associations with Lapse and Post-lapse Emotions”. figshare. https://hdl.handle.net/2134/37935. 
4 Self-Determination in Recreational Exercise: Associations with Lapse and Post-Lapse 5 Emotions

6

7

8

9

10

Word Count: 9849

11

12

13

14

15

16

17

18

19

20

21

22

23

24

25 


\section{Abstract}

27 Objective: Self-determination theory describes how an individual's underlying motives determine self-regulatory outcomes. Building on this, we investigated whether different types of motivation predict lapse in exercise behavior, and particularly the emotional responses to lapse in the form of guilt, anxiety, and relief.

31 Method: Study 1 entailed a self-report, cross-sectional investigation using structural equation modeling to test study hypotheses ( $N=343, M$ age: 24.30 years, 215 female). Study 2 employed a 21-day daily diary using multi-level modeling to test study hypotheses $(N=89$, $M$ age: 25.90 years, 55 female). Motivation was self-reported at the beginning of the study with all other variables self-reported daily.

Results: Autonomous motivation was shown to negatively associate with lapse. When lapse occurred, autonomous motivation was inconsistently associated with the tendency for individuals to feel decreased relief and guilt. In contrast, introjected regulation displayed inconsistent associations with lapse, but increased the likelihood that individuals would experience guilt and anxiety following lapse. External regulation did not reliably predict lapse and emotions across studies.

Conclusions: Our findings suggest autonomous motivation may protect against lapses in goal-directed behavior. Controlling forms of motivation, however, may promote less-optimal emotional processes implicated in poor self-regulation. 


\section{Introduction}

Certain behaviors are essential for good health and overall wellbeing, such as eating healthy foods or performing exercise. Many individuals have knowledge of the wide-ranging benefits, hence, intend to engage in healthy behavior but fail to follow through with their intentions to the detriment of their health (Kothe, Mullan, \& Butow, 2012; Rhodes \& de Bruijn, 2013). These lapses are commonplace for individuals in daily life (Wagner \& Heatherton, 2015). Plans may change, and unexpected events may arise that demand attention. Individuals may not feel like engaging in the planned behavior or forget that they had intentions in the first place (Carver \& Scheier, 2017). These lapses in healthy behavior can lead to significant emotional experiences, which have implications for relapse, goal striving, and disengagement (Shiffman et al., 1996; Webb \& Byrd-Bredbenner, 2015). However, it is poorly understood why these emotional experiences are so variable; a lapse in healthy behavior may offer relief to some (Baumeister \& Heatherton, 1996) but create guilt and anxiety in others (Stetson et al, 2005). The present study adopts a motivational perspective to assess these affective experiences of lapses in exercise behavior.

Motivation is an essential component of human functioning because it provides energy and direction to any planned behavior. Self-determination theory (SDT) is a theory of human motivation that has been widely used to explain adoption and sustainment of healthy behaviors (Ryan \& Deci, 2017). This theory maintains that optimal and durable behavioral engagement is underpinned by autonomous reasons that are interesting and fun (i.e., intrinsic motivation), coherent with all aspects of one's sense of self (i.e., integrated regulation) or personally valuable (i.e., identified regulation). In contrast, controlling motives, such as the desire to avoid feelings of guilt or obtain social approval (i.e., introjected regulation), or external contingencies (i.e., external regulation), are less likely to lead to prolonged and healthy behavioral engagement. A considerable amount of cross-sectional (e.g., Edmunds, 
Ntoumanis, \& Duda, 2006; Vlachopoulos, Kaperoni, \& Moustaka, 2011), experimental (e.g., Edmunds, Ntoumanis, \& Duda, 2008; Silva et al., 2011), longitudinal (e.g., Gunnell, Crocker, Mack, Wilson, \& Zumbo, 2014; Silva et al., 2010; Taylor, Ntoumanis, Standage, \& Spray, 2010), and meta-analytic (Teixeira, Carraça, Markland, Silva, \& Ryan, 2012) evidence supports this contention in exercise and physical activity contexts.

Building on this knowledge, attempts have been made to understand how motivation sustains adaptive behavior. Autonomous motives are positively associated with goal-directed effort (Smith, Ntoumanis, Duda, \& Vansteenkiste, 2011), persistence, challenge appraisals, and task-oriented coping during difficult goal striving (Ntoumanis et al., 2014a), and negatively associated with impulsive attraction to goal-disruptive temptations and the number of obstacles (to goal attainment) encountered (Milyavskaya, Inzlicht, Hope, \& Koestner, 2015). In contrast, controlling motives are unassociated with goal-directed effort (Smith et al., 2011), and positively associated with threat appraisals, disengagement during difficulty (Ntoumanis et al., 2014a), more perceived obstacles and tempting desires (Milyavskaya et al., 2015). Furthermore, personal goal self-concordance (i.e., personal goals pursued for more autonomous reasons) are positively associated with subjective ease in goal pursuit (Werner, Milyavskaya, Foxen-Craft, \& Koestner, 2016).

Nonetheless, there have been limited accounts of how the different motivational regulations work to boost or reduce behavior during instances of goal failure. Autonomous motivation may facilitate greater responsiveness to errors during goal pursuit relative to controlling motivation, however this has been demonstrated in neural signals (i.e., errorrelated negativity), rather than overt behavioral corrections (Legault \& Inzlicht, 2013). When a goal is unattainable, autonomous motives are associated with alternative goal engagement even though disengagement from the original goal is more difficult. In contrast, controlling motives are unassociated with alternative goal reengagement (Ntoumanis et al., 2014b; Smith 
$101 \&$ Ntoumanis, 2014). However, this knowledge does not help us understand persistence in the original goal after failure. A deeper appreciation of goal failure and subsequent reengagement

103 can be gained by investigating the emotional experience during lapses in goal-directed

104 behavior (Marlatt \& Gordon, 1985). Specifically, motivational regulations may lead to

105 different emotional experiences when individuals fail to do planned exercise (Kinnafick,

106 Thøgersen-Ntoumani, \& Duda, 2014).

Experimental and correlational research has shown that, relative to controlling regulations, autonomous regulations are associated with positive emotional experiences

109 during exercise (or at least recalled emotional experiences), such as elevated levels of

110 positive affect (Edmunds et al., 2008), vitality (Gunnell et al., 2014), and enjoyment

111 (Banting, Dimmock, \& Grove, 2011; Murcia, de San Román, Galindo, Alonso, \& González-

112 Cutre, 2008), complementing lower levels of negative affect (Gunnell et al., 2014; Teixeira \&

113 Palmeira, 2016) and social physique anxiety (Thøgersen-Ntoumani \& Ntoumanis, 2007).

114 These emotional benefits may also extend immediately beyond the exercise session and up to

115 three hours after exercise has been completed (Guérin, Fortier, \& Sweet, 2013; Lutz,

116 Lochbaum, \& Turnbow, 2003). This research is valuable but considers emotional response to 117 the activity itself (i.e., what does doing the activity feel like?), it does not help us understand

118 responses to goal failure (i.e., what does not doing the activity feel like?). Filling this gap will

119 help address concerns that psychologists have overlooked processes underlying non-

120 adherence, and particularly the role of affect (Ekkekakis, Zenko, \& Werstein, 2018). Hence,

121 we aim to test the idea that motivational regulations lead to affective experiences that help or inhibit individuals respond from a setback and reengage with exercise. successful goal pursuit and failure (Carver, 2009; Hofmann \& Fisher, 2012; Leventhal \&

125 Zvolensky, 2015). Our decision to investigate these emotions was based on their ability to 
126 guide decision-making and behavior, as well as their conceptual links with specific forms of

127 regulation. Controlling motivation (i.e., a composite of introjected and external regulation)

128 has been associated with affective responses following an inability to achieve goals (Study 2,

129 Ntoumanis et al., 2014b). However, this process is likely to be nuanced depending on the

130 dominant motivational regulation. Introjected regulations may promote self-relevant

131 emotions, such as guilt and anxiety, following a lapse in goal-driven behavior because this

132 regulation is associated with the tendency to self-criticize and goal failure would damage

133 contingent self-esteem (Ryan \& Deci, 2017). In other words, introjected regulation will lead

134 to guilt and anxiety because goal failure represents exactly what the individual is trying to

135 avoid. ${ }^{1}$ Also, introjected regulation should not impact the extent to which lapse elicits

136 feelings of relief given this emotion requires recognition that a threat (e.g., to self) has been

137 avoided (Carver, 2009), rather than realized in the case of a lapse. In contrast, external

138 regulation reflects a wholly external pressure to exercise, hence, goal failure does not conflict

139 with any internalized motive. Alleviating psychological discomfort by not taking part may,

140 therefore, elicit somewhat positive emotional responses (Carver, 2009; Elliot \& Devine,

141 1994). Feelings of relief may follow a slip in exercise behavior, because external regulation

142 reflects a lack of true internalized motive to engage. In comparison to the controlling

143 regulations, autonomous regulations are associated with greater self-acceptance (e.g.,

144 Magnus, Kowalski, \& McHugh, 2010) and acknowledgement of personal limitations. Thus,

145 autonomous regulations may orient individuals to accept occasional failures in goal pursuit

146 and to not experience these failures as a threat to self-identity. Autonomous regulations are,

147 therefore, not likely to be associated with aversive self-relevant emotions, such as guilt and

148 anxiety, or positive feelings of relief following a lapse in exercise behavior.

149 Overview of Present Studies 
Establishing links between an individual's motives and how they are likely to feel

151 following lapse is important, because emotions may influence various processes and

152 outcomes indicative of optimal engagement (Hofmann \& Fisher, 2012; Rhodes \& Kates,

153 2015; Williams et al., 2008). As such, the aim of the present studies was to examine whether

154 individuals' behavioral regulations for exercise were associated with a) the regularity in

155 which individuals reported to lapse in engaging in planned recreational exercise, and b) the

156 emotional experiences of individuals when they fail to do planned recreational exercise (i.e.,

157 guilt, anxiety, and relief). We limited our investigation to recreational exercise given

158 alternative forms of activity, such as competitive sport, have different structural components

159 that make lapse less likely (e.g., formal competitions, selection processes). Study 1

160 represented a cross-sectional investigation of the associations between motives, emotional

161 experiences, and lapses in exercise behavior.

Building upon this study, Study 2 adopted a diary approach to replicate these tests. ${ }^{2}$

163 Across both studies, it was hypothesized that autonomous motives (i.e., intrinsic motivation,

164 integrated regulation, and identified regulation) would be negatively associated with lapses in

165 exercise behavior, whereas introjected and external regulation would be positively associated with lapses in exercise behavior. In terms of emotions following lapse, autonomous regulations lead to greater self-acceptance (Magnus et al., 2010), hence, it was hypothesized to be unrelated to anxiety, guilt, and relief. Introjected regulation was also expected to be unrelated to relief because this would require avoidance of threat (Carver, 2009), whereas a

170 lapse in exercise behavior for an individual regulated through introjection represents a threat that has been realized. Introjected regulation was expected to be positively associated with guilt and anxiety (Ntoumanis et al., 2014b). Finally, external regulation was expected to be positively associated with relief (Carver, 2009) and unrelated to guilt and anxiety. 


\section{Methods}

Participants and Procedures. Structural equation modeling using Mplus software

(Muthén \& Muthén, 1998-2017) was used to investigate study hypotheses, with motivational regulations and emotional experiences modeled as latent factors and questionnaire items as observed indicators. Frequency of lapse was operationalized as an observed variable. As a result of this approach, an apriori sample size calculation (Soper, 2018) suggested a minimum sample size of 345 participants was required. This calculation was based upon an anticipated small effect size (0.25), power of .90, an alpha of 0.05 , nine latent factors, and 34 observed variables (which were the greatest number of factors and variables in our tested models). We also followed the conservative rule-of-thumb of 10 observations per item (i.e., 340 participants; Nunnally, 1967) to guide our participant recruitment. Accordingly, 350 participants $($ Mean age $=24.32$ years, $S D=10.11$ years; 220 females; gender not recorded in three participants) were recruited to take part in this study. Participants were recruited from the general public and from Psychology classes at a university in the United Kingdom.

Students recruited from Psychology classes were offered course credit for their participation. Participants were required to access an online questionnaire (via a link sent to their email account or displayed on a poster), which took approximately fifteen minutes to complete, and to answer questions pertaining to recreational exercise. The questionnaire provided participants with the following definition: 'recreational exercise refers to any planned jog or run, gym session, exercise class, cross-fit or similar activities. This questionnaire does not concern daily physical activity (such as walking or cycling to work) or competitive sport'.

We asked all participants to respond to an adapted three-item questionnaire measuring exercise intentions (Chatzisarantis, Biddle, \& Meek, 1997). The stem was 'please answer the following questions regarding your usual recreational exercise intentions', and the response scale ranged from -3 ('not true at all') to 3 ('completely true'). An example item from this 
scale was 'I usually intend to exercise'. This scale was used to exclude participants from analyses that never usually intend to do recreational exercise. Seven participants scoring -3 participants. Also, 24 participants reported that they never lapsed in exercise plans, hence, their emotional responses were deemed to be invalid and not used in the analysis. Informed consent was received from participants before involvement, and the study was given ethical clearance from the university ethics committee. was measured using the Behavioural Regulations for Exercise Questionnaire-3 (BREQ-3; Markland \& Tobin, 2004; Wilson, Rodgers, Loitz, \& Scime, 2006). This measure has

210 factorial validity and reliability (Markland \& Tobin, 2004) and has six subscales (intrinsic, 211 integrated, identified, introjected, external, and amotivation) each containing four items. As

212 the focus of this study revolved around planned recreational exercise, the amotivation

213 subscale was considered irrelevant to study aims and therefore not included in subsequent

214 data analysis. Example items include: 'I exercise because it is fun' (intrinsic motivation), 'I

215 exercise because it is consistent with my life goals' (integrated regulation), 'It's important to me to exercise regularly' (identified regulation), 'I feel guilty when I don't exercise'

217 (introjected regulation) and 'I exercise because other people say I should' (external regulation). We asked participants to consider 'recreational exercise' and not 'physical exercise' as in the original questionnaire. Individuals then responded to the items using a response scale ranging from 0 ('not true for me') to 4 ('very true for me').

Guilt. Guilt was measured using the six-item guilt subscale of the Positive and valid (Watson \& Clark, 1999) and reliable (Borelli, Nelson-Coffey, River, Birken, \& Moss- 
intended to take part in recreational exercise, but didn't?'. Individuals then completed all six items using a response scale ranging from 1 ('very slightly or not at all') to 5 ('extremely'). Example items include 'guilty' and 'blameworthy'.

Anxiety. Anxiety was measured using the six-item State-Trait Anxiety Inventory short form (Marteau \& Bekker, 1992), which has been shown to have convergent validity and to be reliable (Marteau \& Bekker, 1992). Individuals completed all six items using a response scale ranging from 1 ('not at all') to 4 ('very much'). Example items include 'I feel calm' and 'I am tense'. All positively worded items were reverse scored, so that higher scores reflected higher levels of anxiety.

Relief. Relief was measured using the six-item relief subscale of the Achievement Emotions Questionnaire (Pekrun, Goetz, Titz, \& Perry, 2002). Research has shown this scale to be reliable (Jarrell, Harley, Lajoie, \& Naismith, 2017) and to possess construct and convergent validity (Pekrun, Goetz, Frenzel, Barchfeld, \& Perry, 2011). Individuals completed all six items using a response scale ranging from 1 ('strongly disagree') to 5 ('strongly agree'). Example items include 'I feel relief' and 'I feel freed'.

Frequency of lapses in planned exercise. Frequency of lapses in planned exercise was measured using a single item: 'Following intentions or plans to participate in recreational exercise, how often do you fail to do the activity or session?'. This item was measured on a scale ranging from 1 ('never') through 4 ('some of the time') to 7 ('almost all of the time'). This measurement allowed participants to respond relative to their own level of planned exercise. As such, whether participants plan to engage in exercise once per week or daily did not prevent them from using the full range of responses.

\section{Results}

Preliminary Analysis. For information, descriptive statistics for all variables are presented in Table 1. Confirmatory factor analyses using maximum likelihood estimation was 
conducted to clarify the factor structure of the measurement scales. Indices used to establish model fit were comparative fit index (CFI) close to .95 , root mean square error of approximation $($ RMSEA $)<.10$, and the standardized root mean square $($ SRMR $)<.08(\mathrm{Hu} \&$ Bentler, 1999; MacCallum, Brown, \& Sugawara, 1996; Marsh, Hau, \& Wen, 2004).

High inter-factor correlations (ranging from .78 to .89) among intrinsic, integrated, and identified subscales may have caused analytical problems if retained in their original form (i.e., multicollinearity). Accordingly, these subscales were estimated to load onto a higher order latent factor termed 'autonomous motivation'. This adapted model had acceptable model fit $\left(\mathrm{S}-\mathrm{B} \chi^{2}(164)=442.481, p<.001 ; \mathrm{SRMR}=.05 ; \mathrm{CFI}=.95 ; \mathrm{RMSEA}=\right.$ .07 (90\% CI: .06 to .08), but modification indices suggested estimating a correlation between two items ('I consider exercise part of my identity' and 'I consider exercise a fundamental part of who I am') would improve fit. These items share considerable conceptual overlap, in that they both question the extent to which exercise reflects an important part of participants' identity. Accordingly, this modification was made, and adequate model fit was demonstrated $\left(\mathrm{S}-\mathrm{B} \chi^{2}(163)=333.96, p<.001 ; \mathrm{SRMR}=.05 ; \mathrm{CFI}=.97 ; \mathrm{RMSEA}=.06(90 \% \mathrm{CI}: .05\right.$ to .06$)$. The guilt scale showed satisfactory fit, albeit a somewhat high RMSEA $\left(\mathrm{S}-\mathrm{B} \chi^{2}(9)=\right.$ $67.32, p<.001 ; \mathrm{SRMR}=.03 ; \mathrm{CFI}=.95 ; \mathrm{RMSEA}=.14(90 \% \mathrm{CI}$. .11 to .18$)$. The anxiety (S$\mathrm{B} \chi^{2}(9)=84.40, p<.001 ; \mathrm{SRMR}=.06 ; \mathrm{CFI}=.91 ; \mathrm{RMSEA}=.16(90 \% \mathrm{CI}: .13$ to .20$)$ and relief $\left(\mathrm{S}-\mathrm{B} \chi^{2}(9)=188.52, p<.001 ; \mathrm{SRMR}=.06 ; \mathrm{CFI}=.90 ; \mathrm{RMSEA}=.25(90 \% \mathrm{CI}: .22\right.$ to .28) subscales, however, did not show satisfactory fit and were adapted accordingly. For both subscales, two items ('I am worried' and 'I feel upset' from the anxiety scale; 'I feel relief' and 'I feel freed' from the relief scale) were removed because of the relatively low factor loadings (anxiety: .61 and .46, relief: .74 and .78) and comparatively high error variance (anxiety: .63 and .79, relief: .46 and .40). Acceptable fit was achieved for the modified anxiety $\left(\mathrm{S}-\mathrm{B} \chi^{2}(2)=3.88, p=.14 ; \mathrm{SRMR}=.01 ; \mathrm{CFI}=1.00 ; \mathrm{RMSEA}=.05(90 \% \mathrm{CI}: .00\right.$ to 
$.14)$ and relief $\left(\mathrm{S}-\mathrm{B} \chi^{2}(2)=3.72, p=.07 ; \mathrm{SRMR}=.01 ; \mathrm{CFI}=1.00 ; \mathrm{RMSEA}=.05(90 \% \mathrm{CI}\right.$ : .00 to .13$)$ subscales.

Behavioral regulations predicting frequency of lapse. Autonomous motivation, introjected regulation, and external regulation together explained $29.0 \%$ of the variance in frequency individuals reported to lapse in their planned exercise. Structural fit statistics suggest this model fit the data well $\left(\mathrm{S}-\mathrm{B} \chi^{2}(180)=351.67, p<.001 ; \mathrm{SRMR}=.05 ; \mathrm{CFI}=.97\right.$; RMSEA $=.05$ (90\% CI: .05 to .06)). Bootstrapped (1000 samples) standardized coefficients showed autonomous motivation to be negatively associated $(\beta=-.54,95 \% \mathrm{CI}$ : -.69 to $-.39, p$ $<.001)$, and external regulation to be positively associated $(\beta=.17,95 \% \mathrm{CI}$ : .06 to $.28, p=$ .002) with lapse frequency. No association was found between introjected regulation and lapse frequency $(\beta=.10,95 \% \mathrm{CI}:-.02$ to $.23, p=.13)$. The substantive results did not change following the inclusion of age and gender as covariates, with only minimal changes in statistical parameters.

Behavioral regulations and emotions following lapse. Autonomous motivation, introjected regulation, and external regulation together explained $15.7 \%$ of the variance in anxiety, $48.6 \%$ of the variance in guilt, and $11.4 \%$ of the variance in relief following lapse. Structural fit statistics showed this model to represent a good fit $\left(\mathrm{S}-\mathrm{B} \chi^{2}(508)=885.54, p<\right.$ $.001 ; \mathrm{SRMR}=.05 ; \mathrm{CFI}=.96 ; \mathrm{RMSEA}=.05(90 \% \mathrm{CI}: .04$ to .05$))$. Bootstrapped standardized coefficients showed autonomous motivation to be negatively associated with guilt $(\beta=-.26,95 \%$ CI: -.43 to $-.11, p=.002)$ following lapse, yet unrelated to anxiety $(\beta=$ $.03,95 \%$ CI: -.20 to $.15, p=.71)$ and $\operatorname{relief}(\beta=-.11,95 \%$ CI: -.33 to $.06, p=.25)$. In contrast, introjected regulation was positively associated with feelings of guilt $(\beta=.80,95 \%$ CI: .65 to $.96, p<.001)$ and anxiety $(\beta=.42,95 \%$ CI: .26 to $.58, p<.001)$, but not relief $(\beta=$ $-.15,95 \%$ CI: -.33 to $.07, p=.14)$. Finally, external regulation was not associated with guilt $(\beta=.10,95 \% \mathrm{CI}:-.03$ to $.22, p=.12)$ nor anxiety $(\beta=-.07,95 \% \mathrm{CI}:-.20$ to $.05, p=.27)$, but 
300 positively associated with relief $(\beta=.24,95 \%$ CI: .09 to $.39, p=.002)$ following lapse. The

301 substantive results did not change following the inclusion of age and gender as covariates,

302 with only minimal changes in statistical parameters.

\section{Brief Discussion}

Study 1 provides initial evidence that individuals motivational regulations for recreational exercise are associated with the likelihood of lapsing in exercise behavior and unique emotional responses following the lapse. In line with hypothesized relationships, autonomous motivation and external regulation were associated with less and more lapses in exercise behavior, respectively, and introjected regulation showed no association. Introjected regulation was positively implicated in poor quality emotional experiences following a lapse,

310 with higher anxiety and guilt reported. This is likely because introjected regulation reflects

311 partially internalized pressure to engage in behavior (Ryan \& Deci, 2017). The data also

312 evidenced that external regulation was positively associated with relief, likely due to the

313 motives behind exercise behavior lacking relevance to the self (Carver, 2009). We expected

314 autonomous motivation to be unrelated to emotional experiences following lapse. However,

315 autonomous motivation was negatively associated with guilt, suggesting stronger links with

316 post-lapse emotion than initially thought. It remains possible, however, that links between

317 motivation and lapse prevalence may be explained by differences in planned exercise (i.e.,

318 individual's that plan more exercise each week may be at higher risk of lapse). Accounting

319 for planned exercise may thus enable a better examination of proposed relations.

\section{Study 2}

Study 1 showed that motives underpinning exercise behavior are associated with emotional experiences that have implications for reengagement and long-term behavior.

323 However, the data were cross-sectional, and reports of lapse and emotions were general

324 retrospective accounts which did not refer to a specific lapse event. Hence, Study 2 built upon 
these findings by implementing a diary study over a period of 21 days. Specifically, this study established whether behavioral regulations for exercise predicted (a) the likelihood that individuals lapsed, and (b) the extent to which individuals experienced guilt, anxiety and relief when they did lapse.

\section{Methods}

Participants. Participants were recruited from the public and Psychology classes at a university in the United Kingdom by word of mouth, email, and poster advertisement. Students recruited from Psychology courses were offered course credit for their participation. Eighty-nine participants (Mean age $=25.9$ years, $S D=8.6$ years; 55 females) took part in this study between December 2016 and September 2017. We based our sample size on attempting to obtain at least 50 Level-2 units (i.e., participants) to achieve accurate fixed effects parameter estimates and standard errors (Maas \& Hox, 2005).

Procedure and Measures. Prior to this study, ethical clearance was given by the university ethics committee. Inclusion criteria for this study was that participants had some intention to take part in structured recreational exercise within the next 21-day period. After giving informed consent, participants provided their age, gender, and unique identification number (initials and date of birth), the latter of which helped facilitate anonymous tracking of questionnaires over the data collection period. Participants were provided with the same definition of recreational exercise as used in Study 1. They were then asked to complete an online measure of motivation for recreational exercise (see below), and informed that a researcher would be in touch about the remainder of the study.

Following completion of the initial demographics and motivation questionnaire, participants were asked via email to complete a brief online questionnaire each evening for a period of 21-days. Reminders were sent every two days in the early evening and it was 
suggested to participants that they set-up a calendar reminder on their phone to facilitate questionnaire completion.

Behavioral regulations for recreational exercise. As in Study 1, the BREQ-3

questionnaire was used to measure motivation for recreational exercise. This contextual measure of motivation should partially explain motivation at the situational level (Vallerand, 1997) whilst avoiding common method bias associated with implementing a situational measure of motivation alongside other situational measures (e.g., guilt, anxiety; Podsakoff, MacKenzie, Lee, \& Podsakoff, 2003). Intrinsic, integrated, and identified subscales were again aggregated to form an 'autonomous motivation' variable.

Daily diary questionnaire. Participants recorded their unique participant ID number and the day of the week the questionnaire referred to. Participants were provided with a definition of recreational exercise and asked: 'Did you do recreational exercise today?'. If they answered 'yes', participants moved straight on to questions about the following day's exercise plans. If participants answered 'no', however, they were asked the supplemental question: 'Did you plan to do recreational exercise today?'. If participants answered 'no', they moved on to the questions regarding the following days exercise plans. If they answered 'yes', however, they completed questions measuring the extent to which they experienced guilt, anxiety, and relief following lapse (see below). Therefore, only participants that stated they lapsed (i.e., that they did not do recreational exercise that day, but did plan to) completed questions concerning emotions. All participants then responded to questions about the following day's exercise plans: 'Do you plan or intend to take part in a recreational exercise session tomorrow?' and 'If you do plan on taking part in a recreational exercise session tomorrow, what type of exercise do you plan on doing? If not applicable, type N/A'. Emotions. The two highest loading items from each measure of emotion used in

373 Study 1 were used in this study and were presented following the stem: 'To what extent did 
you feel the following when you intended to exercise today, but didn't?'. The two items used were: 'dissatisfied with self' and 'guilty' (guilt), 'I felt calm' and 'I was upset' (anxiety), and 'I felt relief' and 'I felt free' (relief). The item 'I felt calm' was reverse scored prior to analysis. All response scales were increased to 1-9 to maximize item measurement sensitivity.

Lapse. Lapse was calculated by comparing participants' stated intentions to do planned recreational exercise, with the following day's reported exercise. In other words, participants lapsed if they intended to exercise the following day but did not carry out any planned exercise.

Analysis. Because emotion and lapse data varied within participants over time, a multilevel analysis with repeated measures data clustered within participants was implemented with MLwiN software (version 2.3; Rasbash, Steele, Browne, \& Prosser, 2015). This multilevel approach elicits more accurate standard errors as well as reduced type one error rates, compared to falsely implementing single level regression equations (Nezlek, 2011). Level 2 predictor variables (i.e., motivational regulations) were grand-mean centered. Prior to testing the effects of predictor variables on study outcomes, intercept-only models were constructed for each emotion and lapse to detail the amount of variance at both levels of the outcome variable. Following these base models, main analyses were conducted by adding motivational predictor variables. First, the extent the behavioral regulations predicted whether participants lapsed in their exercise plans was assessed. Lapse was dummy coded (' 1 '= yes; ' 0 '= no) and analyzed using multilevel logistic regression. Second, whether the behavioral regulations predicted guilt, anxiety, and relief was investigated using multilevel linear regression. We also examined whether these results persisted after controlling for planned exercise (i.e., the amount of exercise individuals planned over the 21day measurement period), age and gender. 


\section{Results}

Descriptive Analysis. Out of a possible 1869 daily questionnaires, 1544 were completed (mean number of completed questionnaires per person $=17.35 \pm 4.32$ ). Of the completed questionnaires, $78 \%$ (1200) were completed on the day proposed, with $96 \%$ (1481) completed either on the proposed day or the day after. Participants stated they intended to exercise on the following day on 873 out of 1544 days. Following these intentions, participants recorded the following day that they did not exercise (i.e., lapsed) on 196 occasions $(2.20 \pm 2.19$ lapses per person, range 0 to 11 lapses $)$, they did participate in exercise on 529 occasions ( $5.94 \pm 4.25$ exercise days per person, range 0 to 18 exercise days), and 148 instances were not reported the following day. As such, lapse prevalence rate was $27 \%$ (196 out of 725 occasions). On 34 of the 196 occasions that participants were identified to have lapsed, participants stated the following day that they did not (i.e., participants stated that they did not intend to exercise, even though they reported an intention the preceding day).

Primary Analysis. Our model with lapse as the outcome variable was comparable to binary logistic regression. Hence, this model does not need to meet the assumptions of linearity and normally distributed residuals. The normality of the level 2 residuals of the emotional responses was visually inspected and no major deviations from normality were observed. Correlations between the motivational predictor variables ranged from $r=.03$ to .41 , indicating that multicollinearity was not an issue in the models.

As shown in Table 2 (unadjusted analysis) autonomous motivation was negatively associated with lapse and introjected regulation showed a weak positive trend with lapse. Adjusting for planned exercise, age and gender (Table 3) led to weaker evidence of the association between autonomous motivation and lapse, but more credible evidence of the association between introjected regulation and lapse. No associations were found between 
424 external regulation and lapse in either analysis. In the models investigating the relationships

425

426

427

428

429

430

431

432

433

434

435

436

437

438

439

440

441

442

443

444

445

446

447

448 among motivation and emotional response to lapse, autonomous motivation was negatively associated with relief in both analyses, and weak evidence for a negative association with guilt became more credible when adding the control variables. Autonomous motivation was unrelated to anxiety. Introjected regulation was positively associated with guilt in both analyses. Weak evidence of a positive association between introjected regulation and anxiety became stronger with the inclusion of the control variables. Introjected regulation was unrelated to relief in both analyses. No associations among external regulation and emotions were found.

\section{Brief Discussion}

Study 2 used longitudinal data to demonstrate that contextual motivation (i.e., motives for exercise) predicts lapse in exercise behavior and associated emotional responses. The findings highlight novel distinctions between different motivational regulations. Some evidence demonstrates that motives underpinned by intrinsic value or coherence with one's sense of self can sustain long term health behavior; specifically, through fewer lapses. This process was complemented by no evidence of emotional responses that may compromise future engagement or well-being. In fact, contrasting with hypotheses and Study 1 findings, autonomous motivation may play a role in reducing relief following lapse. In line with hypotheses, but in contrast with findings from Study 1, introjected regulation positively associated with lapse, particularly when controlling for planned exercise. Moreover, introjected regulation again showed positive associations with guilt and anxiety following a lapse. Collectively, these findings substantiate arguments suggesting introjects are insufficient for optimal engagement relative to more autonomous variants of motivation and may even drive disengagement because of adverse emotional consequences (Ryan \& Deci, 2017). In contrast to Study 1 findings, external regulation did not predict lapse or emotions. 
449 This outcome conflicts with our theorizing that relief following lapse would be associated

450 with external regulation because the underlying reasons for participation are not coherent $451 \quad$ with the self.

\section{General Discussion}

Autonomous and controlling motivational regulations differentially predict health behavior engagement ( $\mathrm{Ng}$ et al., 2012). However, despite calls to investigate non-adherence (Ekkekakis et al., 2018), much less is known about whether these motivations can play a role when the behavior is not carried out. As such, the aim of the present studies was to investigate whether individuals' lapses in planned behavior, as well as the associated emotional experiences (i.e., guilt, anxiety, and relief) can be predicted from the underlying reasons individuals have for wanting to engage. Our investigation focused specifically on recreational exercise, thus our results should not be extrapolated to other domains (e.g., competitive sport) because of different motivational factors. Across the two studies, autonomous motivation was a predictor of more adaptive health behavior patterns and less potentially aversive emotional experiences. The link between introjected regulation and lapse was not convincingly demonstrated across the two studies, however, introjected regulation consistently increased the likelihood of poor-quality emotional experiences following a lapse. External regulation played little role in shaping emotional experiences across the two studies. exercise behavior following a lapse was supported, but not when planned exercise was included in the Study 2 analysis. This suggests that the effects of autonomous motivation on exercise (dis)engagement could be indirect via one's exercise intentions (Hagger \& Chatzisarantis, 2009). Autonomous motivation also likely reduced goal failure in the present study by acting as a motivational input to increase the salience of longer-term goals

473 (Berkman, Kahn, \& Livingston, 2016). Hence, autonomously motivated individuals 
474

475

476

477

478

479

480

481

482

483

484

485

486

487

488

489

490

491

492

493

494

495

496

497

498

experience fewer and less intense temptations and obstacles during goal pursuit than counterparts with lower autonomous motivation (Leduc-Cummings et al., 2017; Milyavskaya et al., 2015). Autonomous goals are more chronically and easily activated, relative to controlling goals (Milyavskaya et al., 2015), which makes carrying out intentions an easier and less fatiguing endeavor (Moller, Deci, \& Ryan, 2006).

In addition to behavioral outcomes, our analysis focused on emotional experiences following lapses in goal driven behavior. Stemming from evidence showing autonomously motivated individuals may cope with lapse more adaptively (Weinstein \& Ryan, 2011), we conservatively expected autonomous motivation would not associate with guilt, relief, and anxiety. In fact, the influence of autonomous motivation may be stronger than anticipated.

Across the two studies autonomous motivation was unrelated to anxiety. However, autonomous motivation was negatively associated with relief in the diary study but not the cross-sectional study. We did not hypothesize a negative association between autonomous motivation and relief, but this relationship is conceptually defendable. Relief requires individuals have at least some expectation that a behavior will be threatening (Carver, 2009). Autonomously motivated individuals, on the other hand, experience lower threat responses (Hodgins et al., 2010), so a major ingredient for relief to occur is absent. In addition, it seems incompatible that autonomously motivated individuals would experience relief when they do not do something that they find pleasurable (Banting et al., 2011; Guérin et al., 2013) and enjoyable (Murcia et al., 2008). In addition, autonomous motivation was negatively associated with guilt in the cross-sectional analysis and in the diary study when planned exercise, age and gender was controlled for. Autonomous regulation positively associates with the tendency to be kind to oneself (Magnus et al., 2010), hence, it is plausible that lower guilt occurs when a lapse in intentions occurs. While these findings imply that autonomous motivation may dampen emotional experiences during a temporary lapse that may encourage 
499 long-term behavioral disengagement, the inconsistent nature of our findings suggests caution 500 should be taken with this interpretation.

$501 \quad$ As hypothesized, introjected regulation stimulated feelings of guilt and anxiety

502 following a lapse in behavior across both studies and was unrelated with relief. The large

503 effect sizes suggest that these relationships are substantial. Introjected motives have been

504 implicated in leading to elevated levels of guilt and anxiety previously (e.g., Sabiston et al., 505 2010), but this relationship had yet to be demonstrated during acts of disengagement. The

506 findings align well with theory maintaining that introjected motivated individuals' self-

507 esteem is contingent upon engagement (Ryan \& Deci, 2017). As a result, the pronounced

508 feelings of the guilt and anxiety after a lapse are a manifestation of impaired self-esteem

509 (Crocker \& Park, 2004; Pila et al., 2015). Despite this idea, our findings revealed inconsistent

510 evidence that introjects promote lapse. Our data contradicts the idea that introjects can be

511 powerful motivators in the short-term (Teixeira et al., 2012) or help orient attention to

512 reparatory behaviors (Graton \& Ric, 2017). More likely is that the negatively valanced affect

513 associated with introjected regulation, including guilt, hampers self-control processes

514 (Hofmann \& Fisher, 2012; Muraven, Collins, Morsheimer, Shiffman, \& Paty, 2005; Tice,

515 Bratslavsky, \& Baumeister, 2018). This explains why introjected regulation may not promote

516 long-term behavioral engagement (Pelletier, Fortier, Vallerand \& Briere, 2001) and

517 individuals possessing controlled motives find progress towards their goals a more difficult

518 undertaking (Leduc-Cummings et al., 2017; Werner et al., 2016).

519 As expected, external regulation was unassociated with anxiety and guilt. This finding 520 is consistent with theory maintaining that externally regulated individuals' self-esteem is 521 unlikely to be at stake when a lapse occurs (Ryan \& Deci, 2017). In fact, we expected that 522 external regulation would be positively associated with feelings of relief and lapse, but this 523 was only found in Study 1. External regulation may play less of a role in specific incidents of 
524 lapse, like those investigated in Study 2, compared to the more general processes examined in

Study 1. Moreover, the link between external regulation, lapse and relief may be complex. If the external contingency driving behavior, rather than the behavior itself, represents a threat to the individual of some kind, then failure to carry out the behavior will trigger this threat and not provide relief. Indeed, external regulation in academic contexts, such as the threat of punitive measures for non-engagement, has been shown to positively associate with anxiety

530 (Pekrun et al., 2002). On the contrary, if the behavior poses a greater threat, compared to the contingency, then relief will occur. Overall, it can be concluded that external contingencies, such as incentives and coercions, do not reliably predict goal-directed exercise behavior

533 (Finkelstein et al., 2016; $\mathrm{Ng}$ et al., 2012) and offer little protection in preventing lapse

534 (Marlatt \& Donovan, 2005; Wagner \& Heatherton, 2015).

\section{5}

536

537

538

539

\section{Limitations and Future Directions}

These studies enhance knowledge of the motivational and emotional processes underpinning lapse. Nonetheless, a limitation was that lapse was measured via self-report. Complementary measures of lapse may come in the form of gym attendance records in the exercise domain, biomarkers in response to medication adherence, or parental reports of homework completion in the academic domain. A second future direction would be to investigate the specifics around lapse and exercise disengagement. The reasons individuals give for lapsing may moderate the relationship between motivation and emotions following lapse. For example, greater experiences of guilt and anxiety following lapse may occur due to factors perceived to be controllable (i.e., an individual that does not feel up for exercise), compared to uncontrollable factors (i.e., an individual that is injured; Wagner \& Heatherton, 2015). Similarly, experiences of relief following lapse may be more likely to positively relate to external regulation when lapse is perceived by individuals to free them from external pressures, rather than to expose them to the undesirable consequences which initially 
549 generated the external motives. With respect to the specifics of exercise, the duration of

550 exercise individuals typically engage in may explain lapse likelihood and emotional

551 responding. For instance, failing to complete a 90-minute exercise session may elicit a

552 different emotional response relative to failing to complete a brief 20 -minute bout. Third,

553 individuals' motivation for exercise was only measured at one time-point in the present

554 studies. We made this decision because we wanted to focus on contextually-based motives.

555 Nonetheless, individuals' reasons for engaging in exercise and physical activity contexts can

556 also change over time (Taylor, 2017), particularly in individuals undergoing major changes in

557 their exercise behavior or plans (Silva et al., 2011). Multiple measurements of motivation

558 may better capture these dynamics and may provide more temporally-based evidence linking

559 motivation with emotion and lapse. Finally, we implicated the role of perceived threat in

560 processes involving controlling motivation regulations. It would be of interest to investigate

561 the relative threat posed by the underlying motivation, compared to the behavior, and the

562 different emotional and behavioral consequences.

563 Conclusion

564 This study provides evidence linking individuals' motivational regulation for goal-

565 directed behavior with their post-lapse emotional experiences and tendency to lapse.

566 Specifically, our findings show autonomous motivation is important for reducing the

567 likelihood of lapse. More controlling motives, in contrast, showed weak links with lapse, and

568 in the case of introjected regulation may facilitate self-regulatory failure by promoting

569 maladaptive emotional responses.

570

\section{References}

571 Banting, L. K., Dimmock, J. A., \& Grove, J. R. (2011). The impact of automatically activated motivation on exercise-related outcomes. Journal of Sport and Exercise 
574 Baumeister, R. F., \& Heatherton, T. F. (1996). Self-regulation failure: An

575

576

577

578

579

580

581

582

583

584

585

586

587

588

589

590

591

592

593

594

595

596

597 overview. Psychological inquiry, 7, 1-15. doi: 10.1207/s15327965pli0701_1

Borelli, J. L., Nelson-Coffey, S. K., River, L. M., Birken, S. A., \& Moss-Racusin, C. (2017). Bringing work home: Gender and parenting correlates of work-family guilt among parents of toddlers. Journal of Child and Family Studies, 26, 1734-1745. doi: $10.1007 / \mathrm{s} 10826-017-0693-9$

Carver, C. S. (2009). Threat sensitivity, incentive sensitivity, and the experience of relief. Journal of Personality, 77, 125-138. doi: 10.1111/j.1467-6494.2008.00540.x

Carver, C. S., \& Scheier, M. F. (2017). Self-regulatory functions supporting motivated action. Advances in Motivation Science, 4, 1-37. doi: 10.1016/bs.adms.2017.02.002

Chatzisarantis, N. L., Biddle, S. J., \& Meek, G. A. (1997). A self-determination theory approach to the study of intentions and the intention-behaviour relationship in children's physical activity. British Journal of Health Psychology, 2, 343-360. doi: 10.1111/j.2044-8287.1997.tb00548.x

Crocker, J., \& Park, L. E. (2004). The costly pursuit of self-esteem. Psychological bulletin, 130, 392-414. doi: 10.1037/0033-2909.130.3.392

Edmunds, J., Ntoumanis, N., \& Duda, J. L. (2006). A test of self-determination theory in the exercise domain. Journal of Applied Social Psychology, 36, 2240-2265. doi: 10.1111/j.0021-9029.2006.00102.x

Edmunds, J., Ntoumanis, N., \& Duda, J. L. (2008). Testing a self-determination theory-based teaching style intervention in the exercise domain. European Journal of Social Psychology, 38, 375-388. doi: 10.1002/ejsp.463

Ekkekakis, P., Zenko, Z. \& Werstein, K. M. (2018). Exercise in obesity from the perspective of hedonic theory: A call for sweeping change in professional practice norms. In 

from motivation to adherence, London: Routledge.

Elliot, A. J., \& Devine, P. G. (1994). On the motivational nature of cognitive dissonance: Dissonance as psychological discomfort. Journal of personality and social psychology, 67, 382-394. doi: 10.1037/0022-3514.67.3.382

Enders, C. K., \& Tofighi, D. (2007). Centering predictor variables in cross-sectional multilevel models: a new look at an old issue. Psychological methods, 12, 121-138. doi: 10.1037/1082-989X.12.2.121

Finkelstein, E. A., Haaland, B. A., Bilger, M., Sahasranaman, A., Sloan, R. A., Nang, E. E. incentives to increase physical activity (TRIPPA): a randomised controlled trial. The Lancet Diabetes \& Endocrinology, 4, 983-995. doi: 10.1016/S2213-8587(16)30284-4

Guérin, E., Fortier, M. S., \& Sweet, S. N. (2013). An experience sampling study of physical activity and positive affect: investigating the role of situational motivation and perceived intensity across time. Health psychology research, 1, 100-110. doi: 10.4081/hpr.2013.e21

617 Gunnell, K. E., Crocker, P. R., Mack, D. E., Wilson, P. M., \& Zumbo, B. D. (2014). Goal 618 contents, motivation, psychological need satisfaction, well-being and physical activity: A test of self-determination theory over 6 months. Psychology of Sport and Exercise, 
621 Hagger, M. S., \& Chatzisarantis, N. L. (2009). Integrating the theory of planned behaviour and self-determination theory in health behaviour: A meta-analysis. British journal of health psychology, 14, 275-302. doi: 10.1348/135910708X373959

Hodgins, H. S., Weibust, K. S., Weinstein, N., Shiffman, S., Miller, A., Coombs, G., \& Adair, K. C. (2010). The cost of self-protection: Threat response and performance as a function of autonomous and controlled motivations. Personality and Social Psychology Bulletin, 36, 1101-1114. doi: 10.1177/0146167210375618

Hofmann, W., \& Fisher, R. R. (2012). How guilt and pride shape subsequent self-control. Social Psychological and Personality Science, 3, 682-690. doi: $10.1177 / 1948550611435136$

Jarrell, A., Harley, J. M., Lajoie, S., \& Naismith, L. (2017). Success, failure and emotions: examining the relationship between performance feedback and emotions in diagnostic reasoning. Educational Technology Research and Development, 65, 1263-1284. doi: 10.1007/s11423-017-9521-6

Kinnafick, F. E., Thøgersen-Ntoumani, C., \& Duda, J. L. (2014). Physical Activity Adoption to Adherence, Lapse, and Dropout A Self-Determination Theory Perspective. Qualitative health research, 24, 706-718. doi: 10.1177/1049732314528811 Testing an intervention based on the theory of planned behaviour. Appetite, 58, 9971004. doi: 10.1016/j.appet.2012.02.012

641 Legault, L., \& Inzlicht, M. (2013). Self-determination, self-regulation, and the brain: autonomy improves performance by enhancing neuroaffective responsiveness to selfregulation failure. Journal of Personality and Social Psychology, 105, 123-138. doi: $10.1037 / \mathrm{a} 0030426$ 
645 Leventhal, A. M., \& Zvolensky, M. J. (2015). Anxiety, depression, and cigarette smoking: A transdiagnostic vulnerability framework to understanding emotion-smoking comorbidity. Psychological bulletin, 141, 176-212. doi: 10.1037/bul0000003

Lutz, R., Lochbaum, M., \& Turnbow, K. (2003). The role of relative autonomy in postexercise affect responding. Journal of Sport Behavior, 26, 137-154. Retrieved from: http://eds.b.ebscohost.com/abstract?site $=$ eds\&scope=site\&jrnl $=01627341 \& A N=96911$ 73\&h=5PFBdkry1\%2fXi9ruFXCdUhFTCLK6WUKwSbJlNncRfaUJpsWn9515s0K1H oelzbBb0h5ySt27VXjW4FIiNZt9MyQ\%3d\%3d\&crl=c\&resultLocal=ErrCrlNoResults $\&$ resultNs $=$ Ehost $\&$ crlhashurl=login.aspx $\% 3$ fdirect $\% 3 \mathrm{dtrue} \% 26$ profile $\% 3 \mathrm{dehost} \% 26 \mathrm{sc}$ ope\%3dsite\%26authtype\%3dcrawler\%26jrnl\%3d01627341\%26AN\%3d9691173

Maas, C. J., \& Hox, J. J. (2005). Sufficient sample sizes for multilevel modeling. Methodology, 1, 86-92. doi: 10.1027/1614-2241.1.3.86

MacCallum, R. C., Browne, M. W., \& Sugawara, H. M. (1996). Power analysis and determination of sample size for covariance structure modeling. Psychological methods, 1, 130-149. doi: 10.1037/1082-989X.1.2.130

Magnus, C. M., Kowalski, K. C., \& McHugh, T. L. F. (2010). The role of self-compassion in 661 women's self-determined motives to exercise and exercise-related outcomes. Self and Identity, 9, 363-382. doi: 10.1080/15298860903135073

Markland, D., \& Tobin, V. (2004). A modification to the behavioural regulation in exercise questionnaire to include an assessment of amotivation. Journal of Sport and Exercise Psychology, 26, 191-196. doi: 10.1123/jsep.26.2.191

Marlatt, G. A., \& Donovan, D. M. (Eds.). (2005). Relapse prevention: Maintenance strategies in the treatment of addictive behaviors. Guilford press. Retrieved from: https://www.ipsepa.com/content/uploads/2005-Relapse-prevention-Marlatt- 
670 Marlatt, G. A., \& Gordon, J. R. (1985). Relapse prevention: Maintenance strategies in the treatment of addictive behaviors. New York: Guilford Press.

672

673

674

675

676

677

678

679

680

681

682

683

684

685

686

687

688

689

690

691

692

693

694

Marsh, H. W., Hau, K., \& Wen, Z. (2004). In search of golden rules: Comment on hypothesis-testing approaches to setting cutoff values for fit indexes and dangers in overgeneralizing Hu and Bentler's (1999) findings. Structural Equation Modeling, 11, 320-341. doi:10.1207/s15328007sem1103_2

Marteau, T. M., \& Bekker, H. (1992). The development of a six-item short-form of the state scale of the Spielberger State-Trait Anxiety Inventory (STAI). British Journal of Clinical Psychology, 31, 301-306. doi: 10.1111/j.2044-8260.1992.tb00997.x

Milyavskaya, M., Inzlicht, M., Hope, N., \& Koestner, R. (2015). Saying “no” to temptation: Want-to motivation improves self-regulation by reducing temptation rather than by increasing self-control. Journal of Personality and Social Psychology, 109, 677-693. doi: $10.1037 / \mathrm{pspp} 0000045$

Muraven, M., Collins, R. L., Morsheimer, E. T., Shiffman, S., \& Paty, J. A. (2005). The morning after: limit violations and the self-regulation of alcohol consumption. Psychology of Addictive Behaviors, 19, 253. doi: 10.1037/0893164X.19.3.253

Murcia, J. A. M., de San Román, M. L., Galindo, C. M., Alonso, N., \& González-Cutre, D. (2008). Peers' influence on exercise enjoyment: A self-determination theory approach. Journal of sports science \& medicine, 7, 23-31. Retrieved from: https://www.ncbi.nlm.nih.gov/pmc/articles/PMC3763348/

Muthén, L.K. and Muthén, B.O. (1998-2017). Mplus User's Guide. Eighth Edition. Muthen \& Muthen: Los Angeles, CA.

Nezlek, J. B. (2011). Multilevel modeling for social and personality psychology. London: SAGE Publications Ltd. doi: 10.1111/j.1751-9004.2007.00059.x 
695

696

697

698

699

700

701

702

703

704

705

706

707

708

709

710

711

712

713

714

715

716

717

718

719

Ng, J. Y., Ntoumanis, N., Thøgersen-Ntoumani, C., Deci, E. L., Ryan, R. M., Duda, J. L., \& Williams, G. C. (2012). Self-determination theory applied to health contexts: A metaanalysis. Perspectives on Psychological Science, 7, 325-340. doi: $10.1177 / 1745691612447309$

Ntoumanis, N., Healy, L. C., Sedikides, C., Duda, J., Stewart, B., Smith, A., \& Bond, J. (2014a). When the going gets tough: The "why" of goal striving matters. Journal of personality, 82, 225-236. doi: 10.1111/jopy.12047

Ntoumanis, N., Healy, L. C., Sedikides, C., Smith, A. L., \& Duda, J. L. (2014b). Selfregulatory responses to unattainable goals: the role of goal motives. Self and Identity, 13, 594-612. doi: 10.1080/15298868.2014.889033

Pekrun, R., Goetz, T., Frenzel, A. C., Barchfeld, P., \& Perry, R. P. (2011). Measuring emotions in students' learning and performance: The Achievement Emotions Questionnaire (AEQ). Contemporary educational psychology, 36, 36-48. doi: 10.1016/j.cedpsych.2010.10.002

Pekrun, R., Goetz, T., Titz, W., \& Perry, R. P. (2002). Academic emotions in students' selfregulated learning and achievement: A program of qualitative and quantitative research. Educational psychologist, 37, 91-105. doi: 10.1207/S15326985EP3702_4

Pelletier, L. G., Fortier, M. S., Vallerand, R. J., \& Briere, N. M. (2001). Associations among perceived autonomy support, forms of self-regulation, and persistence: A prospective study. Motivation and emotion, 25, 279-306. doi: 10.1023/A:1014805132406

Pila, E., Sabiston, C. M., Brunet, J., Castonguay, A. L., \& O’Loughlin, J. (2015). Do bodyrelated shame and guilt mediate the association between weight status and selfesteem?. Journal of health psychology, 20, 659-669. doi: 10.1177/1359105315573449

Podsakoff, P. M., MacKenzie, S. B., Lee, J. Y., \& Podsakoff, N. P. (2003). Common method biases in behavioral research: A critical review of the literature and recommended 
remedies. Journal of applied psychology, 88, 879-903. doi: 10.1037/00219010.88.5.879

Rasbash, J., Steele, F., Browne, W., \& Prosser, B. (2015). A user's guide to MLwiN. Centre for Multilevel Modelling, University of Bristol, UK. Retrieved from: http://www.bristol.ac.uk/cmm/media/software/mlwin/downloads/manuals/3-00/manualprint.pdf

Rhodes, R. E., \& de Bruijn, G. J. (2013). How big is the physical activity intention-behaviour gap? A meta-analysis using the action control framework. British journal of health psychology, 18, 296-309. doi: 10.1111/bjhp.12032

Rhodes, R. E., \& Kates, A. (2015). Can the affective response to exercise predict future motives and physical activity behavior? A systematic review of published evidence. Annals of Behavioral Medicine, 49, 715-731. doi: 10.1007/s12160-015-97045

Ryan, R. M., \& Connell, J. P. (1989). Perceived locus of causality and internalization:

Ryan, R. M., \& Deci, E. L. (2017). Self-determination theory: Basic psychological needs in motivation, development, and wellness. New York: Guilford Press.

Sabiston, C. M., Brunet, J., Kowalski, K. C., Wilson, P. M., Mack, D. E., \& Crocker, P. R. (2010). The role of body-related self-conscious emotions in motivating women's physical activity. Journal of Sport and Exercise Psychology, 32, 417-437. doi: $10.1123 /$ jsep.32.4.417 Progression from a smoking lapse to relapse: Prediction from abstinence violation 
effects, nicotine dependence, and lapse characteristics. Journal of Consulting and Clinical Psychology, 64, 993-1002. doi: 10.1037/0022-006X.64.5.993

Silva, M. N., Markland, D., Carraça, E. V., Vieira, P. N., Coutinho, S. R., Minderico, C. S., ... \& Teixeira, P. J. (2011). Exercise autonomous motivation predicts 3-yr weight loss in women. Medicine \& Science in Sports \& Exercise, 43, 728-737. doi: 10.1249/MSS.0b013e3181f3818f

Silva, M. N., Vieira, P. N., Coutinho, S. R., Minderico, C. S., Matos, M. G., Sardinha, L. B., \& Teixeira, P. J. (2010). Using self-determination theory to promote physical activity and weight control: a randomized controlled trial in women. Journal of behavioral medicine, 33, 110-122. doi: 10.1007/s10865-009-9239-y

Smith, A. L., \& Ntoumanis, N. (2014). An examination of goal motives and athletes' selfregulatory responses to unattainable goals. International Journal of Sport Psychology, 45, 538-558. doi: 10.7352/IJSP 2014.45.538azin

Smith, A. L., Ntoumanis, N., Duda, J. L., \& Vansteenkiste, M. (2011). Goal striving, coping, and well-being: A prospective investigation of the self-concordance model in sport. Journal of Sport and Exercise Psychology, 33, 124-145. doi:

\section{$10.1123 /$ jsep.33.1.124}

Soper, D.S. (2018). A-priori Sample Size Calculator for Structural Equation Models [Software]. Retrieved from http://www.danielsoper.com/statcalc

Stetson, B. A., Beacham, A. O., Frommelt, S. J., Boutelle, K. N., Cole, J. D., Ziegler, C. H., \& Looney, S. W. (2005). Exercise slips in high-risk situations and activity patterns in long-term exercisers: An application of the relapse prevention model. Annals of Behavioral Medicine, 30, 25-35. doi: 10.1207/s15324796abm3001 4 
767

768

769

770

771

772

773

774

775

776

777

778

779

780

781

782

783

784

785

786

787

788

789

790

791

Taylor, I. M. (2017). Reciprocal effects of motivation in physical education and self-reported physical activity. Psychology of Sport and Exercise, 31, 131-138. doi: 10.1016/j.psychsport.2017.01.003

Taylor, I. M., Ntoumanis, N., Standage, M., \& Spray, C. M. (2010). Motivational predictors of physical education students' effort, exercise intentions, and leisure-time physical activity: A multilevel linear growth analysis. Journal of Sport and Exercise Psychology, 32, 99-120. doi: 10.1123/jsep.32.1.99

Teixeira, D. S., \& Palmeira, A. L. (2016). Needs Satisfaction Effect on Exercise Emotional Response: A Serial Mediation Analysis with Motivational Regulations and Exercise Intensity. Motriz: Revista de Educação Física, 22, 368-375. doi: 10.1590/S19806574201600040023

Teixeira, P. J., Carraça, E. V., Markland, D., Silva, M. N., \& Ryan, R. M. (2012). Exercise, physical activity, and self-determination theory: a systematic review. International Journal of Behavioral Nutrition and Physical Activity, 9, 78-107. doi: 10.1186/1479$5868-9-78$

Thøgersen-Ntoumani, C., \& Ntoumanis, N. (2007). A self-determination theory approach to the study of body image concerns, self-presentation and self-perceptions in a sample of aerobic instructors. Journal of Health Psychology, 12, 301-315. doi: $10.1177 / 1359105307074267$

Tice, D. M., Bratslavsky, E., \& Baumeister, R. F. (2018). Emotional distress regulation takes precedence over impulse control: If you feel bad, do it!. In Self-Regulation and SelfControl (pp. 275-306). Routledge. Retrieved from: https://www.apa.org/pubs/journals/releases/psp80153.pdf

Vallerand, R. J. (1997). Toward a hierarchical model of intrinsic and extrinsic motivation. In M.P. Zanna (Ed.), Advances in experimental social psychology (Vol. 29, pp. 271-360). 
New York: Academic Press. Retrieved from: https://www.sciencedirect.com/science/article/pii/S0065260108600192

Vlachopoulos, S. P., Kaperoni, M., \& Moustaka, F. C. (2011). The relationship of selfdetermination theory variables to exercise identity. Psychology of sport and exercise, 12, 265-272. doi: 10.1016/j.psychsport.2010.11.006

Wagner, D. D., \& Heatherton, T. F. (2015). Self-regulation and its failure: The seven deadly threats to self-regulation. APA handbook of personality and social psychology, 1, 805842. doi: $10.1037 / 14341-000$

Watson, D., \& Clark, L. A. (1999). The PANAS-X: Manual for the positive and negative affect schedule-expanded form. Iowa City, IA: University of Iowa. doi: 10.1111/j.17424658.2010.07754.x

Webb, D., \& Byrd-Bredbenner, C. (2015). Overcoming consumer inertia to dietary guidance. Advances in Nutrition, 6, 391-396. doi: 10.3945/an.115.008441

Weinstein, N., \& Ryan, R. M. (2011). A self-determination theory approach to understanding stress incursion and responses. Stress and Health, 27, 4-17. doi: 10.1002/smi.1368

Werner, K. M., Milyavskaya, M., Foxen-Craft, E., \& Koestner, R. (2016). Some goals just feel easier: Self-concordance leads to goal progress through subjective ease, not effort. Personality and Individual Differences, 96, 237-242. doi: 10.1016/j.paid.2016.03.002

Williams, D. M., Dunsiger, S., Ciccolo, J. T., Lewis, B. A., Albrecht, A. E., \& Marcus, B. H. (2008). Acute affective response to a moderate-intensity exercise stimulus predicts physical activity participation 6 and 12 months later. Psychology of sport and exercise, 9, 231-245. doi: 10.1016/j.psychsport.2007.04.002 
815 Wilson, P. M., Rodgers, W. M., Loitz, C. C., \& Scime, G. (2006). "It's who I am... Really!'

816 The importance of integrated regulation in exercise contexts. Journal of Applied

817 Biobehavioral Research, 11, 79-104. doi: 10.1111/j.1751-9861

818

819

820

821

822

823

824

825

826

827

828

829

830

831

832

833

834

835

836

837

838

839 
${ }^{1}$ Although related, introjected regulation is distinct from feelings of guilt because the

842 former construct reflects the preceding desire to avoid such emotion, rather than the

843 consequential affective state per se.

$844 \quad{ }^{2}$ In the diary study, we also attempted to investigate whether motives for exercise

845 predicted speed of reengagement in exercise following lapse. However, due to several

846 limitations, including a large number of uncompleted responses to this variable and

847 systematic bias, we did not include this variable in this article. 
Table 1. Descriptive statistics and zero-order correlations for Study 1 variables.

\begin{tabular}{|c|c|c|c|c|c|c|c|c|c|c|c|c|c|c|}
\hline & & \multirow[b]{2}{*}{ Mean } & \multirow[b]{2}{*}{$S D$} & \multirow[b]{2}{*}{$\begin{array}{c}\text { Potential } \\
\text { Range }\end{array}$} & \multicolumn{10}{|c|}{ Correlations } \\
\hline & & & & & 1 & 2 & 3 & 4 & 5 & 6 & 7 & 8 & 9 & 10 \\
\hline 1 & $\mathrm{Age}^{\mathrm{a}}$ & 24.30 & 10.10 & - & & & & & & & & & & \\
\hline 2 & Gender $^{\mathrm{b}}$ & .37 & .48 & - & $.17^{* *}$ & & & & & & & & & \\
\hline 3 & Intrinsic motivation $^{\mathrm{c}}$ & 2.84 & 0.92 & $0-5$ & .06 & .09 & & & & & & & & \\
\hline 4 & Integrated regulation $^{\mathrm{c}}$ & 2.33 & 1.21 & $0-5$ & $.15^{* *}$ & $.21 * *$ & $.74 * *$ & & & & & & & \\
\hline 5 & Identified regulation $^{\mathrm{c}}$ & 2.96 & 0.89 & $0-5$ & $.14^{*}$ & $.16^{* *}$ & $.77 * *$ & $.83^{* *}$ & & & & & & \\
\hline 6 & Introjected regulation ${ }^{\mathrm{c}}$ & 2.20 & 1.04 & $0-5$ & -.04 & .01 & $.43 * *$ & $.52 * *$ & $.57 * *$ & & & & & \\
\hline 7 & External regulation ${ }^{\mathrm{c}}$ & 0.77 & 0.85 & $0-5$ & $-.17 * *$ & -.04 & $-.13^{*}$ & $-.11^{*}$ & -.09 & $.14^{*}$ & & & & \\
\hline 8 & Anxiety $^{d}$ & 2.49 & 0.70 & $1-4$ & .04 & $-.16^{* *}$ & $.15^{* *}$ & $.17^{* *}$ & $.25^{* *}$ & $.39^{* *}$ & .07 & & & \\
\hline 9 & Guilt $^{\mathrm{d}}$ & 2.69 & 1.03 & $1-5$ & $-.17 * *$ & $-.13^{*}$ & .10 & $.19^{* *}$ & $.23 * *$ & $.57^{* *}$ & $.23^{* *}$ & $.44^{* *}$ & & \\
\hline 10 & Relief $^{d}$ & 1.58 & 0.75 & $1-5$ & .01 & .03 & $-.21 * *$ & $-.24 * *$ & $-.28 * *$ & $-.19 * *$ & $.19^{* *}$ & $-.19 * *$ & .09 & \\
\hline 11 & Likelihood of lapse $\mathrm{e}^{\mathrm{e}}$ & 3.14 & 1.34 & $1-7$ & -.10 & -.09 & $-.41 * *$ & $-.47 * *$ & $-.45^{* *}$ & $-.19 * *$ & $.24^{* *}$ & -.09 & -.02 & $.20 * *$ \\
\hline
\end{tabular}

Note. $S D=$ Standard deviation; Gender: $0=$ female; $1=$ male.

${ }^{\mathrm{a}} N=339 ;{ }^{\mathrm{b}} N=341 ;{ }^{\mathrm{c}} N=342 ;{ }^{\mathrm{d}} N=319 ;{ }^{\mathrm{e}} N=343$.

$* p<.05 * * p<.01$. 
Table 2. Multilevel models investigating motivational predictors of lapse in planned exercise and post-lapse emotional responses.

\begin{tabular}{|c|c|c|c|c|c|c|c|c|}
\hline \multirow[b]{2}{*}{ Predictor } & \multicolumn{2}{|l|}{ Lapse } & \multicolumn{2}{|l|}{ Guilt } & \multicolumn{2}{|l|}{ Anxiety } & \multicolumn{2}{|l|}{ Relief } \\
\hline & OR $(95 \% \mathrm{CI})$ & $p$ & $b(95 \% \mathrm{CI})$ & $p$ & $b(95 \% \mathrm{CI})$ & $p$ & $b(95 \% \mathrm{CI})$ & $p$ \\
\hline Intercept & $0.56(0.48,0.65)$ & $<.001$ & $4.69(4.24,5.15)$ & $<.001$ & $4.35(3.95,4.74)$ & $<.001$ & $2.57(2.26,2.88)$ & $<.001$ \\
\hline $\begin{array}{l}\text { Autonomous } \\
\text { motivation }\end{array}$ & $0.81(0.66,0.99)$ & .04 & $-0.57(-1.21,0.08)$ & .08 & $0.21(-0.35,0.77)$ & .46 & $-0.50(-0.94,-0.06)$ & .03 \\
\hline $\begin{array}{l}\text { Introjected } \\
\text { regulation }\end{array}$ & $1.20(0.99,1.45)$ & .07 & $0.66(0.03,1.29)$ & .04 & $0.51(-0.03,1.06)$ & .07 & $0.02(-0.42,0.45)$ & .95 \\
\hline $\begin{array}{l}\text { External } \\
\text { regulation }\end{array}$ & $0.92(0.71,1.18)$ & .50 & $-0.33(-1.15,0.50)$ & .43 & $0.10(-0.61,0.81)$ & .78 & $-0.48(-1.04,0.08)$ & .09 \\
\hline Level 1 error & - & - & $2.71(2.07,3.35)$ & $<.001$ & $1.68(1.28,2.08)$ & $<.001$ & $0.96(0.73,1.18)$ & $<.001$ \\
\hline Level 2 error & $1.22(1.07,1.38)$ & .002 & $2.28(1.09,3.47)$ & $<.001$ & $1.85(0.96,2.74)$ & $<.001$ & $1.21(0.64,1.77)$ & $<.001$ \\
\hline
\end{tabular}

Note. $\mathrm{OR}=$ Odds ratio; $\mathrm{CI}=$ Confidence interval; Multilevel logistic regression used to estimate lapse. 
Table 3. Multilevel models investigating motivational predictors of lapse in planned exercise and post-lapse emotional responses, controlling for the amount of exercise planned over the 21-day measurement period, age and gender.

\begin{tabular}{|c|c|c|c|c|c|c|c|c|}
\hline \multirow[b]{2}{*}{ Predictor } & \multicolumn{2}{|l|}{ Lapse } & \multicolumn{2}{|l|}{ Guilt } & \multicolumn{2}{|l|}{ Anxiety } & \multicolumn{2}{|l|}{ Relief } \\
\hline & OR $(95 \% \mathrm{CI})$ & $p$ & $b(95 \% \mathrm{CI})$ & $p$ & $b(95 \% \mathrm{CI})$ & $p$ & $b(95 \% \mathrm{CI})$ & $p$ \\
\hline Intercept & $0.57(0.49,0.65)$ & $<.001$ & $4.58(4.12,5.04)$ & $<.001$ & $4.17(3.80,4.55)$ & $<.001$ & $2.66(2.37,2.96)$ & $<.001$ \\
\hline $\begin{array}{l}\text { Autonomous } \\
\text { motivation }\end{array}$ & $0.88(0.72,1.07)$ & .21 & $-0.70(-1.37,-0.02)$ & .04 & $0.03(-0.51,0.58)$ & .91 & $-0.47(-0.90,-0.04)$ & .03 \\
\hline Introjected regulation & $1.22(1.01,1.47)$ & .04 & $0.78(0.15,1.41)$ & .02 & $0.71(0.20,1.22)$ & .01 & $-0.06(-0.46,0.35)$ & .79 \\
\hline External regulation & $1.06(0.83,1.34)$ & .66 & $-0.29(-1.11,0.54)$ & .49 & $0.30(-0.37,0.97)$ & .38 & $-0.42(-0.95,0.10)$ & .12 \\
\hline Planned exercise & $0.97(0.94,1.00)$ & .03 & $0.09(-0.01,0.20)$ & .09 & $0.11(0.02,0.20)$ & .01 & $-0.09(-0.15,-0.02)$ & .01 \\
\hline Age & $0.98(0.96,1.00)$ & .01 & $-0.01(-0.06,0.05)$ & .80 & $0.01(-0.04,0.05)$ & .79 & $0.04(0.00,0.08)$ & .03 \\
\hline Gender & $0.75(0.56,1.00)$ & .05 & $-0.30(-1.33,0.73)$ & .56 & $-1.11(-1.95,-0.28)$ & .01 & $0.03(-0.64,0.69)$ & .94 \\
\hline Level 1 error & - & - & $2.71(2.07,3.36)$ & $<.001$ & $1.68(1.28,2.07)$ & $<.001$ & $0.96(0.73,1.18)$ & $<.001$ \\
\hline Level 2 error & $1.16(1.04,1.30)$ & .01 & $2.07(0.96,3.19)$ & $<.001$ & $1.41(0.67,2.14)$ & $<.001$ & $0.92(0.46,1.39)$ & $<.001$ \\
\hline
\end{tabular}

Note. $\mathrm{OR}=$ Odds ratio; $\mathrm{CI}=$ Confidence interval; Gender: $0=$ female; $1=$ male; Multilevel logistic regression used to estimate lapse. 


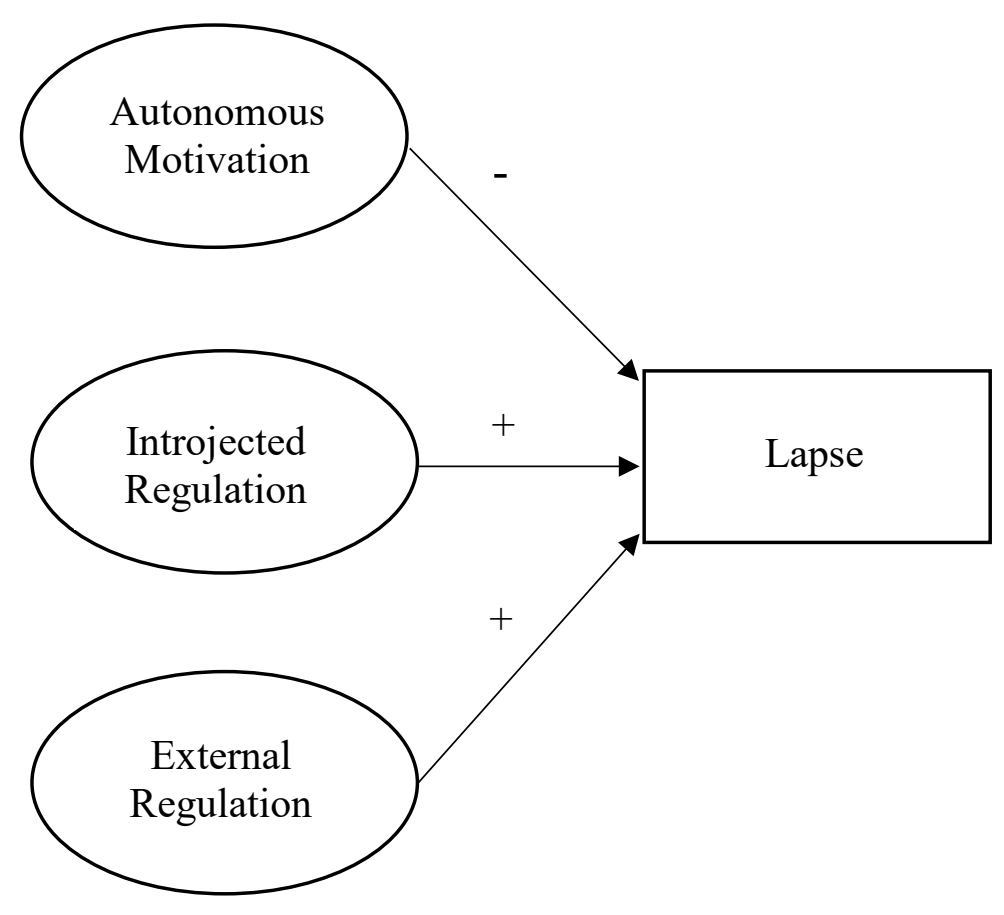

Figure 1. Model depicting hypotheses in Study 1 between autonomous motivation, introjected regulation, external regulation, and likelihood of lapse in planned exercise.

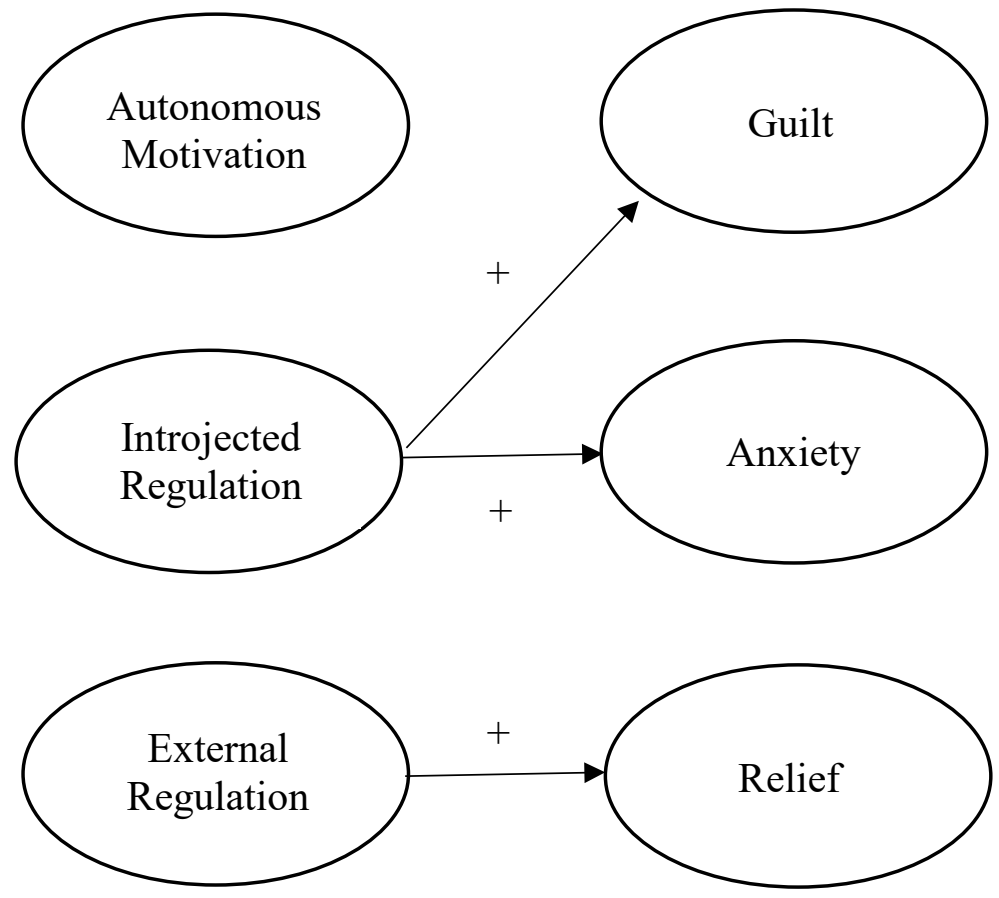

Figure 2. Model depicting hypotheses in Study 1 between autonomous motivation, introjected regulation, external regulation, and guilt, anxiety, and relief following lapse in planned exercise. 